\title{
ALTERAÇÕES CLÍNICAS E LABORATORIAIS DE CÃES E GATOS COM DOENÇA RENAL CRÔNICA: REVISÃO DA LITERATURA
}

\author{
GALVÃO, André Luiz Baptista ${ }^{1}$ \\ BORGES, Juliana Corrêa ${ }^{2}$ \\ VIEIRA, Manuela Cristina ${ }^{1}$ \\ FERREIRA, Guadalupe ${ }^{3}$ \\ LÉGA, Elzylene ${ }^{4}$ \\ PINTO, Mildre ${ }^{5}$
}

Recebido em: 2010-02-23

Aprovado em:2010-03-27

ISSUE DOI: $10.3738 / 1982.2278-368$

RESUMO: Os rins têm papel de destaque na manutenção da vida, pois desempenham um conjunto de funções que garantem a homeostase do organismo. A doença renal crônica (DRC) é usualmente observada em cães e gatos e independente da etiologia, é caracterizada por lesões estruturais irreversíveis, que podem evoluir progressivamente para falência renal. Na DRC ocorre a incapacidade de executar adequadamente as funções de manutenção do equilíbrio hidroeletrolítico e ácido-base, excreção de catabólitos e regulação hormonal. Estima-se que somente após a perda irreversível de mais de $75 \%$ da capacidade funcional, inicia-se a manifestação dos sinais de uremia, cuja intensidade varia em cada paciente. O gradual aumento da disfunção renal compromete também a capacidade funcional de outros órgãos, resultando no aparecimento da síndrome urêmica. Os exames complementares como urinálise, hemograma, bioquímicos séricos e urinários permitem elucidar o grau de comprometimento renal e estabelecer a melhor conduta terapêutica a ser realizada. Desse modo, os exames laboratoriais possuem grande relevância, pois auxiliam no diagnóstico e prognóstico, caracterizando o estágio de evolução da enfermidade e orientando as condutas terapêuticas a serem adotadas. Assim, descrever as manifestações sistêmicas promovidas pela doença renal crônica em pequenos animais e correlacionar com os achados laboratoriais é o objetivo da presente revisão literária.

Palavras-chave: Azotemia. Insuficiência. Uremia.

\section{CLINICAL AND LABORATORY ALTERATIONS OF DOGS AND CATS WITH CHRONIC KIDNEY DISEASE - REVISION OF LITERATURE}

SUMMARY: Kidneys have important function in the maintenance of life, because they carry out many roles that maintain homeostasis organism. The chronic kidney disease (CKD) is common in dogs and cats, but independent aetiology disease, is characterized by irreversible structural lesions, that can develop progressively for chronic renal failure. CKD is the incapacity executing the functions maintain the balance hidroelectrolytic and acid-base, catabolic excretion and hormonal regulation appropriately. After more $75 \%$ of irreversible functional loss capacity, begins uremia signs, whose intensity varies in each patient one. The gradual increase of

\footnotetext{
${ }^{1}$ Pós-graduando em Medicina Veterinária da Faculdade de Ciências Agrárias e Veterinárias, - Universidade Estadual Paulista (FCAV/UNESP) - Jaboticabal. Via de Aceso "Prof Dr. Paulo Donato Castellane" Km 05, 14.884-900, Jaboticabal -SP. Brasil.

2 Docente do Departamento de Morfologia e Fisiologia Animal da Faculdade de Ciências Agrárias e Veterinárias, - Universidade Estadual Paulista (FCAV/UNESP) - Jaboticabal

${ }^{3}$ Médica Veterinária Autônoma

${ }^{4}$ Docente e Coordenadora do Curso de Graduação em Medicina Veterinária da Faculdade Dr. Francisco Maeda FAFRAM - Fundação Educacional de Ituverava-SP.

${ }^{5}$ Docente do Setor de Diagnóstico por Imagem do Centro Universitário Barão de Mauá - Ribeirão Preto-SP
} 
the renal dysfunction also commits the functional other organs capacity resulting in uremic syndrome. Complementary exams as urinalysis, blood count complete, biochemical serum and urinary allow to elucidate the degree renal compromising and to establish the better therapeutics conduct to be accomplished. This way, laboratory exams are very relevance, because aid in the diagnosis and prognostic, characterizing the evolution illness, guiding the therapeutic conducts to be taken. Therefore, describe systemic manifestations promoted by the chronic kidney disease and correlate with laboratory exams is the objective the present literary revision.

Keywords: Azotemia. Failure. Uremia.

\section{INTRODUÇÃO}

O sistema urinário é de grande importância para diferentes funções orgânicas. O rim é um órgão importante para manutenção da homeostase, que regula os volumes do líquido extracelular e do sangue, a pressão arterial sistêmica, a produção de eritrócitos, a excreção de catabólitos nitrogenados, o equilíbrio de eletrólitos e o equilíbrio ácido-base (POLZIN et al., 2000).

A doença renal crônica (DRC) é caracterizada por lesões estruturais irreversíveis, que podem evoluir progressivamente para uremia, insuficiência renal crônica (IRC) e falência renal (POLZIN et al., 2000). Após a instalação inicial da lesão renal, ocorrem mudanças estruturais e funcionais adaptativas dos néfrons remanescentes, na tentativa de manter a homeostase, principalmente quanto à regulação do volume e da composição do fluido corporal extracelular. Eventualmente, essas mudanças adaptativas tornam-se excessivas ou ineficientes, favorecendo, ainda mais, o desenvolvimento de dano dos néfrons (POLZIN et al., 2005; SHIMIZU, 2005).

A mudança adaptativa consiste no aumento do volume de filtração glomerular e do aporte sanguíneo dos néfrons remanescentes, com consequente hipertrofia e hipertensão dos glomérulos, na tentativa de manter a taxa de filtração glomerular (TFG), e atenuar a diminuição do clearance de creatinina, deste modo exacerba-se a agressão hemodinâmica ao glomérulo, e em consequiência estabelece-se um ciclo vicioso que leva, ao final do processo, à completa destruição do parênquima renal (SHIMIZU, 2005).

Depois de estabelecida a DRC, a magnitude da disfunção renal geralmente permanece estável por meses ou declina vagarosamente no decorrer de meses a anos. Não é necessário que o processo responsável pela lesão inicial, esteja presente para que ocorra uma disfunção progressiva ( JACOB, 2002 ). O gradual aumento da disfunção renal compromete também a capacidade funcional de outros órgãos, tais como digestório (SENIOR, 1994; POLZIN et al., 2000), cardiovascular (ROSS, 1992), esquelético, nervoso ( POLZIN; OSBORNE, 1986 ) e hematopoético (SENIOR, 2001). As manifestações clínicas ocorrem isoladamente ou em conjunto, resultando no aparecimento da síndrome urêmica (POLZIN et al., 2000). 
$\mathrm{Na}$ tentativa de padronização de prognóstico e tratamentos adequados ao grau de severidade da DRC, a International Renal Interest Society (IRIS, 2006) dividiu a mesma em estágios:

- Estágio I (não azotêmico): ausência de sinais clínicos evidentes de uremia, exceto poliúria e polidipsia e creatinina sérica menor que $1,4 \mathrm{mg} / \mathrm{dL}$ para cães e inferior $1,6 \mathrm{mg} / \mathrm{dL}$ para gatos.

- Estágio II (azotemia renal discreta): ausência de sinais clínicos evidentes de uremia, exceto poliúria e polidipsia e creatinina sérica entre 1,4 e 2,0mg/dL para cães e entre 1,6 e $2,8 \mathrm{mg} / \mathrm{dL}$ para gatos.

- Estágio III (azotemia renal moderada): sinais clínicos moderados de uremia e creatinina sérica entre 2,1 e 5,0mg/dL para cães e entre 2,9 e 5,0mg/dL para gatos.

- $\quad$ Estágio IV (azotemia renal severa): sinais clínicos graves de uremia e creatinina sérica superior que 5,0mg/dL para cães e gatos.

Dentro de cada estágio, o paciente é subcategorizado de acordo com o grau de proteinúria e pressão sistêmica arterial. Os estágios II e III incluem pacientes com IRC, onde a presença de azotemia reflete a perda de mais de dois terços de néfrons funcionais. O termo falência renal é aplicado aos pacientes categorizados no estágio IV (IRIS, 2006).

A azotemia e hiperfosfatemia são as alterações mais comuns na bioquímica sérica durante a evolução da DRC, sendo decorrentes da diminuição da TFG. A urinálise, o hemograma, as dosagens de eletrólitos séricos e urinários, permitem estabelecer o grau de uremia apresentado pelo paciente, como também, o quanto da função renal pode estar deficiente, servindo de parâmetro para qual conduta terapêutica seguir.

Desse modo, os exames complementares são de grande relevância, pois auxiliam no diagnóstico, caracterizam o estágio de evolução da enfermidade, orientam as condutas terapêuticas a serem tomadas e provável prognóstico. Assim, descrever as manifestações sistêmicas promovidas pela doença renal crônica em pequenos animais e correlacionar com os achados laboratoriais é o objetivo da presente revisão literária.

\section{ASPETOS CLÍNICOS E LABORATORIAIS DA DRC}

O início e a apresentação dos episódios clínicos e bioquímicos que ocorrem em pacientes com DRC podem variar, dependendo da natureza, gravidade, duração, velocidade de progressão da afecção subjacente, presença de enfermidade coexistente, mas não relacionada com a idade e espécie do paciente, e administração de agentes terapêuticos (POLZIN et al., 2000). 
A uremia é o estado clínico para qual convergem todas as moléstias renais, generalizadas e progressivas, sendo definida como a presença de quantidades anormais de constituintes da urina no sangue, associada a uma síndrome tóxica polissistêmica (DHONT et al., 2000).

Nos cães, as manifestações clínicas mais precoces observadas durante a evolução da DRC são a poliúria, polidipsia e noctúria, de intensidade variada, e que ocorrem quando há comprometimento de cerca de $66 \%$ do parênquima renal, com a perda da capacidade de concentração urinária (NICHOLS, 2001). Em fase posterior, quando há comprometimento de $70 \%$ a $75 \%$ dos néfrons, inicia-se o acúmulo de compostos nitrogenados não protéicos na circulação sanguínea, devido à diminuição da TFG, quando então as consequências sistêmicas do quadro de IRC são inúmeras e a uremia pode estar presente em graus variados (POLZIN; OSBORNE, 1995).

Durante a evolução da DRC, a conservação de água dada pela capacidade de concentrar a urina fica comprometida. O aumento da velocidade do fluxo intraluminal e o desarranjo estrutural do parênquima causam uma diminuição da tonicidade medular, e comprometimento do sistema de contracorrente, fazendo com que o insuficiente renal não tolere privação prolongada de água, e apresente uma desidratação hipertônica, que pode ser agravada por outras perdas hídricas, tais como: vômito, diarréia e adipsia (habitualmente presentes na síndrome urêmica). A desidratação intensa pode acarretar em hipoperfusão dos rins, prejudicando ainda mais a função renal (ZATZ, 2000; GREGORY, 2005).

O paciente com DRC pode estar na fase oligúrica (débito urinário inferior a 1,0mL/kg/hora) ou não oligúrica, a DRC geralmente é caracterizada por poliúria. Entretanto, os animais podem estar transitoriamente oligúricos, quando desidratados, ou a oligúria podese desenvolver durante a descompensação na fase terminal (CHEW, 2000).

As desordens no sistema digestório compreendem a anorexia e a perda de peso, que são achados comuns, porém inespecíficos, que podem anteceder outros sinais de uremia. A anorexia está associada a múltiplos fatores, dentre eles, o envolvimento da elevação sérica de toxinas urêmicas, principalmente a leptina ( POLZIN et al., 2005; VANHOLDER; LAECKE, 2008). O vômito é um achado frequente, porém inconsistente, e decorrente da ação de toxinas urêmicas sobre a zona quimiorreceptora do centro bulbar do vômito, e da gastroenterite urêmica (DHONT et al., 2000). A hipergastrinemia é decorrente da diminuição da excreção renal da gastrina, acarretando na hiperacidez gástrica, que culmina em ulceração e/ou lesão na mucosa estomacal e intestinal ocasionando hemorragia e subsequente hematemese, melena ou hematoquesia. Ainda, a degradação da uréia em amônia 
por ação da urease sintetizada por bactérias, pode contribuir para o desenvolvimento de úlceras no estômago e na cavidade oral, podendo evoluir a para glossite necrosante (ZATZ, 2000).

No sistema hematopoético, a anemia é um dos achados mais comuns em cães com DRC (KING et al., 1992; MACDOUGALL, 2001). Múltiplos fatores favorecem o desenvolvimento de anemia do tipo normocítica, normocrômica, não regenerativa observada durante a progressão da DRC em cães. Como causas da anemia na DRC são apontadas: (1) redução na expectativa de vida do eritrócito, em parte devido à elevação nos níveis de paratormônio (PTH) e das toxinas urêmicas; (2) redução da concentração de glutationa eritrocitária, que induz a diminuição de deformidade e aumento da fragilidade osmótica das células vermelhas (MACDOUGALL, 2001; BURANAKARI et al., 2008). Outros fatores podem colaborar para anemia no paciente com DRC: (1) deficiência de folatos e vitamina B (as vitaminas hidrossolúveis são perdidas/eliminadas devido à poliúria e pela ingestão insuficientes); (2) deficiência de ferro (decorrente da ingestão prejudicada e/ou absorção prejudicada no intestino); (3) neoplasias; (4) processos inflamatórios; (5) fibrose de medula óssea secundária ao hiperparatireoidismo e a (6) deficiência de eritropoetina em estágios finais de DRC (COWGILL, 1992). Os sinais clínicos referentes à anemia incluem as mucosas pálidas, fadiga, letargia e anorexia (POLZIN et al., 2005). A hemorragia presente em alguns pacientes é resultante de trombastenia e de anormalidades da interação entre as plaquetas e a parede vascular. As produções de plaquetas e dos fatores da coagulação estão normais em pacientes com DRC (CHEW; DIBARTOLA, 1989).

Em casos de profunda anemia, mecanismos compensatórios são acionados, como o aumento das concentrações eritrocitárias de 2,3 difosforoglicerato, a redução à resistência periférica vascular e a elevação do débito cardíaco, fatores esses para facilitar a oxigenação dos tecidos periféricos (RODRIGUEZ et al., 1994; POLZIN et al., 2000). A elevação sérica do 2,3 difosforoglicerato eritrocitário ocorre de forma compensatória à anemia crônica, promovendo um desvio para direita na curva de dissociação do oxigênio, aumentando a sua distribuição para os tecidos (KING et al., 1992; RODRIGUEZ et al., 1994).

Outra causa discutida sobre a anemia em pequenos animais com DRC é a deficiência de eritropoetina, argumento amparado pela hipótese de que com a redução da massa renal, que ocorre diminuição de sua produção (KING et al., 1992; COOK; LOTHROP, 1994; POLZIN et al., 2005).

No sistema esquelético, as elevadas concentrações circulantes de PTH e consequente desenvolvimento de hiperparatireoidismo acarretam no aparecimento de alterações ósseas 
principalmente na mandíbula e na maxila dos cães. Os ossos, devido ao grau de desmineralização, comprometem os dentes, resultando na inserção imprópria na arcada dentária, e a proliferação marcante de tecido conjuntivo, que pode evoluir para uma distorção facial (POLZIN; OSBORNE, 1995).

A hipertensão sistêmica é uma das complicações cardiovasculares mais frequentemente reconhecidas da DRC em cães e gatos, considerando-se que ocorrem em 50 a 93\% dos cães acometidos (COWGILL; KALLET, 1986), sendo principalmente de origem secundária (ACIERNO; LABATO, 2005). Ainda, a hipertensão arterial pode ser detectada em 85\% dos cães com doença glomerular (BARTGES, 1996). Não se conhece o mecanismo exato etiológico da hipertensão associada a DRC, não tendo sido demonstrado nenhum fator isolado responsável pelo seu estabelecimento (DARKE et al., 2000). Provavelmente, vários fatores em combinação levam ao desenvolvimento de uma hipertensão sistêmica secundária, a saber: (1) ativação do sistema renina-angiotensina-aldosterona, assim expansão do volume do líquido extracelular; (2) aumento dos níveis séricos de epinefrina e norepinefrina; (3) aumento da resposta vascular a norepinefrina; (4) diminuição da atividade do sistema cinina-calicreína; (5) aumento do débito cardíaco; (6) vasopressina, cuja elevação ajuda promover vasoconstrição, além de exercer feito prolongado de reduzir a excreção hídrica pelos rins e (7) aumento da resistência periférica (ROSS, 1992; SCHIFFRIN et al., 2007).

Recentemente vários estudos de Xu et al. (2005), Schiffrin et al., (2007), Desir (2008), Schlaich et al. (2009) e Desir (2009) demonstraram um novo fator relacionado à hipertensão arterial presente nos pacientes renais crônicos humanos, devido a uma deficiência de uma amina oxidase, denominada renalase oxidase. Acredita-se, que esta enzima, seja produzida nos rins e que tenha uma participação na regulação da função cardíaca, e da pressão arterial, por atuar na degradação das catecolaminas séricas, promovendo uma diminuição da pressão arterial. Xu et al. (2005) descreveram o efeito da renalase oxidase em ratos como um agente inotrópico negativo no coração e como hipotensor, bem como, Desir ( 2009 ) descreveu a diminuição sérica da renalase oxidase, correlacionada com uma diminuição na TFG em pacientes renais crônicos com hipertensão.

A elevação da pressão sanguínea sistêmica pode apressar a progressão da DRC (TOTO et al., 1995). A hipertensão sistêmica é identificada como um fator de risco expressivo para o desenvolvimento de insuficiência renal terminal (KLAG et al., 1996; SCHIFFRIN et al., 2007). Estudos realizados por Jacob et al. ( 2003 ) demonstraram que uma alta da pressão sanguínea sistólica no momento do diagnóstico inicial da DRC em cães, é associada com um risco aumentado de ocorrência de crise urêmica, risco de morte e taxa de declínio da função 
renal. No seu estudo, $31 \%$ dos cães apresentaram hipertensão secundária a DRC, e com mau prognóstico. A elevação da pressão arterial sistêmica perpetua o dano vascular e aumenta a resistência vascular periférica e renal, a qual induz a progressão da DRC, e acentua a hipertensão arterial (STILES et al., 1994). Desta maneira, os órgãos mais afetados são os que estão envolvidos na regulação do fluxo sanguíneo (o coração) e os que contêm extensas redes arteriolares ou capilares (os olhos, o cérebro, os rins) (ACIERNO; LABATO, 2005). A hipertrofia e fibrose do ventrículo esquerdo do coração é consequência comum da hipertensão arterial, e resulta em queda da tensão da parede do miocárdio (SCHIFFRIN et al., 2007; GREGORY, 2009). Isto capacita o coração suplantar a pós-carga aumentada resultante da maior resistência periférica. Não está esclarecido o mecanismo pelo qual o estímulo hemodinâmico da sobrecarga de pressão resulta em hipertrofia ventricular (MUNAGALA et al., 2005). Outros fatores, podem também influenciar a resposta cardíaca nos casos de hipertensão arterial, como o aumento da pré-carga (sobrecarga de volume), devido à expansão do volume vascular e ao aumento da contratilidade, em decorrência da maior estimulação adrenérgica (FROLICH, 1993). O ventrículo hipertrofiado pode estar sob maior risco de isquemia, devido às quedas relativas no fluxo sanguíneo das artérias coronárias (LONDON et al., 1996). A hipertrofia ventricular pode ser tão grave a ponto de causar disfunção cardíaca congestiva, mas se a pressão sanguínea for controlada a hipertrofia pode regredir (ROSS, 1992; MUNAGALA et al., 2005).

$\mathrm{Na} \mathrm{DRC}$, as consequências clínicas da hipertensão arterial dependem tanto da gravidade, quanto da duração do aumento na pressão arterial, os olhos também podem ser acometidos, principalmente quando a pressão arterial sistólica é igual ou superior a 180 mmHg (STEPIEN, 2002). Doenças oculares e retinopatias têm sido associadas a hipertensão e relatadas em cães e em gatos com DRC (STILES et al., 1994, GREGORY, 2009) . As lesões oculares características para estes casos são (1) o estreitamento e perda da tortuosidade das artérias retinianas mais calibrosas, em associação com leve hipertensão arterial, ou vasos dilatados, tortuosos, nos casos de hipertensão arterial mais grave; (2) manchas algodonosas na retina, que são formadas pelo acúmulo de organelas celulares na camada de fibras nervosas da retina, em decorrência de lesões dos axônios; (3) hemorragias; (4) exsudatos; (5) descolamentos da retina e (6) papiledema (STEPIEN, 2002; ACIERNO; LABATO, 2005).

Desordens decorrentes da ação direta do acúmulo de toxinas urêmicas, da hipertensão arterial secundária, e do hiperparatireoidismo secundário renal levam ao aparecimento de sinais clínicos neuromusculares, como cabeça torta, ataxia, apatia, desorientação, mioclonias, convulsões e coma, com prognóstico reservado (ACIERNO; LABATO, 2005). 
Embora ocorra uma variação em parâmetros informados na literatura, geralmente é considerado hipertenso o cão ou gato que apresente uma pressão arterial sistólica igual ou superior a 170mmHg em pelo menos três medidas tomadas em tempos diferentes (TILLEY, 2008). A IRIS (2006) caracterizou valores para cães e gatos com doença renal crônica, a pressão arterial sistólica de 130 a $150 \mathrm{mmHg}$ de mínimo risco, de 150 a $160 \mathrm{mmHg}$ de baixo risco, de 160 a $180 \mathrm{mmHg}$ moderado risco e superior a $180 \mathrm{mmHg}$ de alto risco.

$\mathrm{Na}$ hemogasometria, pode ser observada acidose metabólica, decorrente de: (1) diminuição da capacidade de excreção de íon hidrogênio pela amoniogênese renal, (2) diminuição da excreção renal de composto de fosfato e sulfato, (3) redução de prótons pelas células tubulares e (4) reabsorção tubular de bicarbonato. A acidose metabólica frequentemente é bem compensada em pacientes com DRC, que se encontram estabilizados devido à adaptação renal tubular, e mecanismo respiratório compensatório. Entretanto, pacientes com DRC descompensados, frequentemente apresentam acidose metabólica grave (CHEW, 2000).

A acidose metabólica beneficia o desenvolvimento da anorexia, náusea, vômito, letargia, fraqueza, perda muscular (induz o catabolismo muscular), perda de peso e má nutrição. Ainda, a acidose predispõe à perda urinária de cálcio e, por mecanismos compensatórios, à reabsorção óssea e ao comprometimento da síntese de calcitriol (SUTTON; DIRKS, 1996). A acidemia intensa pode ocasionar a diminuição do débito cardíaco, da pressão arterial, dos fluxos sanguíneos nos rins e hepático, e a centralização do volume sanguíneo (POLZIN et al., 2000).

A azotemia e hiperfosfatemia são as alterações mais comuns de bioquímica sérica de pacientes com DRC, sendo decorrentes da diminuição da TFG. Na maioria das vezes ambos os aumentos ocorrem em paralelo. O aumento na atividade sérica do PTH está diretamente relacionado ao grau de hiperfosfatemia (LAZARETTI et al., 2006). Atualmente, o PTH está sendo considerado, por muitos pesquisadores como uma toxina urêmica capaz de provocar vários distúrbios orgânicos, além de ser o principal responsável pelo desequilíbrio no metabolismo de cálcio, dos pacientes com DRC (VANHOLDER; SMET, 1999; DHONT et al., 2000; VANHOLDER; LAECKE, 2008).

A concentração sérica de creatinina é um indicador mais preciso da função renal quando comparada a uréia, pois ao contrário desta, não é consideravelmente influenciada por hemorragias gastrintestinais, além de não ser reabsorvida pelos túbulos. Contudo, a concentração sérica de creatinina pode variar em função da massa muscular (FINCO, 1995; MEYER et al., 1995). Ainda, de acordo com Watson; Church ( 1981 ) demonstraram que a 
creatinina, a exemplo da uréia responde de forma variável ao tipo da dieta ingerida, indicando que este fator deve ser levado em consideração ao se interpretar valores séricos de uréia e creatinina. De acordo com Levey et al. (1989) devido à conversão da creatina em creatinina pelo calor, ocorre grande ingestão de creatinina através do consumo de carne cozida. Epstein, (1984) demonstrou que dieta comercial para cães altera a concentração sérica de uréia, mas não a da creatinina. Adicionalmente, o dano tecidual ativo pode causar aumentos dos valores de creatinina sérica, apesar de tal fato ser raro em pequenos animais (CENTER, 1985).

É importante advertir que as toxinas urêmicas estão envolvidas na manifestação clínica da uremia, e que não há um composto isolado responsável pelo início dos sinais clínicos. Os compostos como a uréia e a creatinina são considerados marcadores laboratoriais, isto é, podem indicar, indiretamente, a diminuição da TFG (RIGOIR, 1997; VANHOLDER; SMET, 1999; DHONT et al., 2000).

$\mathrm{O}$ aumento do fósforo na circulação sanguínea ocorre na DRC, principalmente nos estágios mais avançados da doença (POLZIN et al., 2005). Segundo estudo realizado por NASSAR (2000), a presença de hiperfosfatemia foi constatada em $87 \%$ dos casos e o aumento da concentração sérica de PTH em 93\%, observando-se correlação positiva entre os dois parâmetros. A elevação da concentração sérica de fósforo parece estimular diretamente a secreção do PTH e assim, desenvolve-se o hiperparatireoidismo secundário renal na tentativa de regular o desequilíbrio do metabolismo de cálcio e fósforo. Uma das ações do PTH é de mobilizar o cálcio dos ossos (promovendo a reabsorção óssea), o que dificulta em picos de hipercalcemia, a qual favorece a deposição de sais de cálcio, em tecidos moles (calcificação metastática ) e principalmente nos rins, ocasionando perda ainda maior de néfrons (OSBORNE et al., 1995; VANHOLDER; SMET, 1999; DHONT et al. 2000). Além disso, a perda de tecido renal funcional leva a uma diminuição da atividade da vitamina $\mathrm{D}$, pela enzima 1- $\alpha$-hidroxilase presente nos rins, o que também é um fator estimulador da secreção de PTH (BROWN et al., 1997).

A hipocalcemia parece ser um achado relativamente comum na DRC, sobretudo associada à hiperfosfatemia e baixas concentrações séricas de calcitriol (POLZIN et al., 2000). A hipocalcemia é detectada mais frequentemente quando se avalia a fração do cálcio biologicamente ativa o cálcio ionizado, do que pela determinação somente do cálcio total sérico (KOGIKA, 2002).

O cálcio ionizado é um componente do cálcio plasmático, que é considerado como a fração mais importante do cálcio, por estar envolvido em os processos fisiológicos tais como: (1) regulação da secreção e ação hormonal (PTH e 1,25 diidroxivitamina D); (2) transporte de 
íons; (3) contração muscular; (4) coagulação sanguínea; (5) mineralização de ossos e (6) integridade de membranas plasmáticas (FELDMAN, 1995).

A hipercalcemia também é descrita em cães com DRC, em valores de cálcio total maiores que $12 \mathrm{mg} / \mathrm{dL}$. O mecanismo pelo qual se desenvolve a hipercalcemia é complexo ou multifatorial, envolvendo o (1) aumento da reabsorção óssea mediada pelo PTH; (2) a secreção autônoma de PTH pelas paratireóides; (3) a menor degradação e eliminação do PTH e de seus metabólitos pelos rins; (4) a diminuição da excreção renal de cálcio devido à redução da TFG; (5) o aumento da reabsorção de cálcio intestinal devido ao aumento da sensibilidade ao calcitriol e a (6) elevação da fração de cálcio ligado a proteínas ou formando complexos com os ânions (citrato, bicarbonato, fosfato ou sulfato) (CHEW; CAROTHERS, 1989).

Nos pacientes com DRC tem sido reportado a atividade do PTH como um estimulador quimiotático de leucócitos, porém as células podem apresentar deficiência em sua capacidade de ação (SHAUL et al., 2001; KRALOVA et al., 2009). O mecanismo responsável por esta ação deficiente dos leucócitos, principalmente dos neutrófilos no paciente DRC, não está bem esclarecido. São discutidos os seguintes fatores de influência: (1) deficiência de zinco; (2) aumento do cálcio intracelular; (3) anemia; (4) deficiência nutricional do paciente; e (5) o aumento do ferro (KRALOVA et al., 2009).

Devido ao aumento da atividade osteoclástica associada ao hiperparatireoidismo secundário renal, pode-se encontrar uma elevação sérica da enzima fosfatase alcalina, que geralmente não excede de quatro a seis vezes ao seu valor máximo de normalidade (CENTER, 1992).

Em relação às concentrações séricas de sódio e potássio, os mecanismos de regulação do sódio e do potássio são preservados até os estágios avançados da DRC ( CHEW; DIBARTOLA, 1989). No entanto, em um estudo realizado por Silva (2002), em cães em estágios finais de DRC naturalmente adquirida, ficou demonstrado aumento significativo da excreção fracionada de sódio, e a diminuição significativa da concentração sérica deste íon. A presença da hipocalemia é mais comum em gatos na fase poliúrica (LAPPIN, 2004). Porém, a hipocalemia pode se desenvolver em cães e gatos pela ingestão imprópria do eletrólito, pela excessiva perda gastrintestinal (êmese crônica) ou urinária (administração de diuréticos) e pela translocação do potássio do meio extracelular para o meio intracelular (alcalose metabólica). As alterações clínicas que podem ser observadas na hipocalemia são: fraqueza muscular, poliúria, polidipsia, anorexia e taquicardia. Nas fases finais da DRC, em que o paciente evolui para oligúria, tanto cães quanto gatos, podem apresentar hipercalemia, com 
suas consequências sobre o ritmo cardíaco (bradicardia e parada atrial, nos casos mais graves) (CHEW, 2000; LAPPIN, 2004).

A hipermagnesenemia é descrita em cães com insuficiência renal, pois os rins são os órgãos responsáveis pela excreção do magnésio, embora o mecanismo envolvido no controle sérico deste eletrólito não seja bem esclarecido (POLZIN et al., 2005).

$\mathrm{Na}$ urinálise, podem ser observadas isostenúria (1.008 e 1.012 - densidade urinária semelhante à do plasma) (MEYER et al., 1995; POLZIN et al., 2000). No pH urinário, são descritas associadas a condições fisiológicas ou a diversas desordens, por exemplo: é observado maior tendência em excretar urina ácida, quando em acidose respiratória ou metabólica, pirexia, catabolismo de proteínas, diarréia e êmese. Ainda, a proteinúria apresenta-se de intensidade variada e poucos elementos no sedimento urinário (OSBORNE et al., 1995).

A proteinúria de origem renal é decorrente de alterações estruturais na barreira glomerular, que causam a passagem de maior quantidade de proteína em direção ao filtrado glomerular, e/ou decorrência da não reabsorção destas proteínas pelos túbulos proximais. Esse tipo de proteinúria pode ser achado nos casos de glomerulonefrite, amiloidose, síndrome de Fanconi, intoxicação com antibióticos aminoglicosídeos e metais pesados (GREGORY, 2009).

White et al. (1988) demonstraram em cães, alta correlação entre o valor de excreção de proteina urinária em 24 horas e a relação proteína :creatinina urinária (RP/C) de amostras de urinas aleatórias, fundamentando-se no fato de que a creatinina é produzida numa taxa constante, é livremente filtrada pelo glomérulo e não é significativamente secretada nem reabsorvida pelos túbulos renais. Jacob et al. (2003) mostraram que uma RP/C maior que 1,0 em 45 cães em estágios finais de DRC foi associada com um maior risco de desenvolvimento de crise urêmica e morte em comparação com cães cujas RP/C eram menores que 1,0. Estes autores, portanto, concluíram que a determinação da RP/C em cães com DRC de ocorrência natural pode ser usada com valor prognóstico. Atualmente a IRIS (2006), classificou valores da RP/C para cães entre 0,0 a 0,2 como não proteinúricos, de 0,21 a 0,49 são considerados valores de caráter reservado e quando acima de 0,5 são classificados como proteinúricos; e para gatos valores da $\mathrm{RP} / \mathrm{C}$ entre 0,0 a 0,2 como não proteinúricos, de 0,21 a 0,39 são considerados valores de caráter reservado e quando acima de 0,4 são classificados como proteinúricos.

Estudos realizados em humanos demonstraram a existência da relação entre proteinúria e hipertensão, visto que o controle terapêutico da última está implicado em uma 
diminuição da magnitude da primeira (GRAUER et al., 2000; GREGORY, 2009). A correlação de hipertensão e proteinúria têm sido descritas em cães com diabetes mellitus (Struble et al., 1998), com hiperadrenocorticismo (ORTEGA et al., 1996), bem como com DRC (REGO, 2006; WEHNER et al., 2008).

A ativação do sistema renina-angiotensina-aldosterona está diretamente relacionada com a hipertensão arterial e também provoca a proteinúria. A hipertensão capilar glomerular leva um aumento da permeabilidade glomerular e excessiva filtração de proteínas (GREGORY, 2009). Este sistema também pode causar proteinúria através da expressão de nefrina. Esta é uma proteína constituinte do diafragma das fendas inter-podais dos podócitos glomerulares. Por manter a integridade do diafragma das fendas, a nefrina limita a perda de proteínas pelo glomérulo. Quando sua expressão é alterada, ocorre a proteinúria. Proteínas presentes na urina são tóxicas para os túbulos e podem provocar inflamação tubulointersticial e podem provocar inflamação tubulointersticial, fibrose e morte celular (GREGORY, 2005; SHIMIZU, 2005; SCOTT, 2008). A proteinúria pode estar presente como consequência de lesões glomerulares e/ou tubulares (GREGORY, 2005; GREGORY, 2009). Usualmente, proteinúria de maior intensidade é observada nas doenças glomerulares. As doenças túbulosintersticiais que evoluem para DRC apresentam proteinúria, de intensidade discreta ou até mesmo ausente (FINCO, 1995; GREGORY, 2009). O desfecho de uma proteinúria de elevada intensidade pode ser a síndrome nefrótica, caracterizada por hipoalbuminemia, edema, ascite, hipercolesteremia, hipertensão e hipercoagulabilidade (GREGORY, 2005).

\section{CONCLUSÃO}

De acordo com Grauer (1994), pelo caráter irreversível e, frequentemente, progressivo das lesões, o tratamento realizado nos pacientes em diferentes estágios da DRC visa reduzir o trabalho renal, aliviar os sinais clínicos e evitar a progressão das lesões renais.

Portanto a participação dos exames complementares, associado as manifestações clínicas do animal, é de grande valor, pois identifica o estágio de sua evolução da doença renal crônica, estabelecendo a conduta terapêutica adequada para cada caso e o presumível prognóstico do paciente.

\section{REFERÊNCIAS}

ACIERNO, M.J.; LABATO, A. 2005. Hypertension in renal disease: diagnosis and treatment. Clin. Tech. Small Anim. Pract. 20:23-30. 
BARTGES, J. W. 1996. Hypertension and renal disease. Vet. Clin. North Am. 26:13311345.

BROWN, S.A.; CROWELL, W. A., BROWN J.A., BARSANTI J.A.; FINCO, D.R. 1997. Pathophysiology and Management of Progressive Renal Disease. Vet. J. 154:93-109.

BURANAKARI, C.et al. 2008. Relationships between oxidative stress markers and red blood cell characteristics in renal azotemic dogs. Res. Vet. Sci. v.10, p.1010-103.

CENTER, S.A. Fisiopatologia e diagnóstico laboratorial das moléstias hepáticas, p.123. In: ETTINGER ,S.J.; FELDMAN, E.C. (ed.) Tratado de medicina veterinária interna. 3.ed. São Paulo: Manole, 1992. v. 1.

CENTER, S.A. 24-hour urine protein/creatinine ratio in dogs with protein-losing nephropathies. J. Am. Vet. Med. Assoc. n.187, p.820-24, 1985.

CHEW, D.J. Fluid therapy during intrinsic renal failure p.210-227. In: DIBARTOLA, S.P. (ed.) Fluid therapy in small animal practice. 2 ed. Philadelphia: W. B. Saunders Company, 2000 .

CHEW, D.J.; CAROTHERS, M. Hypercalcemia. Vet. Clin. North Am. n.19, p.265-287, 1989.

CHEW, D.J.; DIBARTOLA, S.P. Diagnosis and pathophysiology of renal disease p.18931961. In: ETTINGER, S. J.; FELDMAN, E.C. (ed.) Textbook of veterinary internal medicine, 3 th. W. B. Saunders, Philadelphia.1989. v.2.

COOK, S.M.; LOTHROP, C.D. Serum erythropoietin concentration measured by radioummunoassay in normal, polycythemic and anaemic dogs and cats. J. Vet. Int. Med. n.8, p.18-25, 1994.

COWGILL, L. Pathophysiology and Management of Anemia in chronic progressive renal failure. Sem. Vet. Med. Surg . n.7, p.175-182, 1992.

COWGILL, L.; KALLET, A. Systemic hypertension, p.360-364..In: Kierk, R. Current veterinary therapy IX (ed.) Philadelphia: W. B. Saunders Company, 1986.

DARKE, P., BONAGURA, J.D.; KELLY, D.F. Doenças Cardiovasculares, p.134-135. In: DARKE, P., BONAGURA, J.D.; KELLY D.F. (ed.) Cardiologia Veterinária. São Paulo: Manole, 2000.

DESIR, G.V. Regulation of blood pressure and cardiovascular function by renalase. Kidney Int. n.76, p.366-370, 2009.

DESIR, G.V. Renalase deficiency in chronic kidney disease, and its contribution to hypertension and cardiovascular disease. Curr. Opin. Nephrol. Hypertens. n.17, p. 181$185,2008$.

DHONT, A.; VANHOLDER, R.; BIESEN, V.W; Lamiere, N. The removal of uremic toxins. Kidney Int. S58:S47-S58. 2000. 
EPSTEIN, B.S. Postprandial changes in plasma urea nitrogen and plasma creatinina concentrations in dogs fed commercial diets. J. Amer. Anim. Hosp. Assoc. n.20, p.779-782, 1984.

FELDMAN, E.C. Disorders of the parathyroid glands. p.1437-1461. In: Ettinger, S. J.; Feldman E.C. Textbook of veterinary internal medicine. 4th. Philadelphia: W. B. Saunders. 1995.v.2.

FINCO, D R. Applied physiology of the kidney p. 26-46. In: OSBORNE, C.A.; FINCO, D.R. Canine and Feline Nephrology and Urology. 2th. Willians \& Willkins:Philadelphia. 1995.

FROLICH, E.D. 1993. The heart in hypertension. N. Engl. J. Med. n.328, p.212-213, 1995.

GRAUER G. F. Testes diagnósticos para o sistema urinário p. 334-385. In: NELSON R.W.; COUTO C.G. (ed.) Fundamentos de medicina interna de pequenos animais. Rio de Janeiro: Guanabara Koogan, 1994.

GRAUER, G.F.et. al. Effects of enalapril versus placebo as a treatment for canine idiopathic glomerulonephritis. J. Vet. Int. Med. n.14, p.526-533, 2000.

GREGORY, G.F. Diagnosis, management of hypertension, proteinúria in dogs with chronic renal disease: DMV Newsmagazine. Disponível na internet:

$<$ http://veterinarynews.dvm360.com/dvm/Medicine/Diagnosis-management-of-hypertensionproteinuria-i/ArticleStandard/Article/detail/591639? contextCategoryId=45705>. 11 ago.

2009.

GREGORY, F.G. Early detection of renal damage and disease in dogs and cats. Vet. Clin.

North Am. n. 35, p.281-296, 2005.

IRIS. International Renal Interest Society. Staging Chronic Kidney Disease (CKD). Disponível na Internet: 〈http://www.iris-kidney.com/pdf/IRIS\%20A4\%20Poster.pdf >. 10 set.2006.

JACOB, F. Clinical evolution of dietary modification for treatment of spontaneous chronic renal failure in dogs. J. Am. Vet. Med. Assoc. n.220, p.1163-1170, 2002.

JACOB, F.et al. Association between initial systolic blood pressure and risk of developing a uremic crisis or of dying in dogs with chronic renal failure. J. Am. Vet. Med. Assoc. n.222, p.322-329, 2003.

KING, L.G.et al. Anemia of chornic Renal Failure in dogs, J. Vet. Intern. Med. n.6, p.326$332,1992$.

KLAG, M. J.et al. Blood pressure and end-stage renal disease in men. N. Engl. J. Med. n.334, p.13-18, 1996.

KOGIKA, M.M. Avaliação do cálcio sérico ionizado em cães sadios e em cães com insuficiência renal crônica e acidose metabólica. 2002, 134f. Tese (Livre docência em clínica veterinária), Faculdade de Medicina Veterinária e Zootecnia, Universidade de São Paulo. 
KRALOVA. S.; LEVA, L.; TORMAN, M. Polymorphonuclear function in naturally occurring renal failure in dogs. Veterinarni Medicina, Czech, v. 54, n. 5, p. 236-243, 2009.

LAPPIN, R. M. Poliúria e Polidipsia: Visão Geral e Plano de Diagnóstico p.225-241. In: LAPPIN, R. M. (ed.) Segredos em medicina interna felina. São Paulo Artmed, 2004.

LAZARETTI, P.et al. Concentração sérica de paratormônio intacto em cães com insuficiência renal crônica. Arq. Bras. Med. Vet. Zootec. n.58, p.489-494, 2006.

LEVEY A.S.et al. Creatinine filtration, secretion and excretion during progressive renal disease. Kidney Int. n.36, p.S73-S80, 1989.

LONDON, G.M.et al. Cardiac and arterial interactions in end-stage renal disease. Kidney Int. n.50, p.600-608, 1996.

MACDOUGALL, R.C. Role of uremic toxins in exacerbating anemia in renal failure. Kidney Int. n.59, p.S67-S72, 2001.

MEYER, D.J.; COLES, E.H.; RICH L.J. Anormalidades em testes do trato urinário p.63-72. In: MEYER, D.J.; COLES, E.H.; RICH, L.J. (ed.) Medicina de laboratório veterinária: interpretação e diagnóstico. Roca, São Paulo. 1995.

MUNAGALA, V.K.et al. Ventricular structure and function in aged dogs with renal hypertension. Circ. Res. n.111, p.1128-1135, 2005.

NASSAR, P.L. Avaliação da concentração sérica de paratormônio intacto (PTHi), pelo método imunofluorométrico, em cães hígidos e cães com insuficiência renal crônica em hiperazotemia. 93 f. 2000. Dissertação (Mestrado em medicina veterinária), Faculdade de Medicina Veterinária e Zootecnia, Universidade de São Paulo.

NICHOLS, R. Polyuria and Polydipsia. Vet. Clin. North Am. Small Anim. Pract. n.31:833. 2001.

POLZIN, D. J.; OSBORNE, C. A. Dietary Management of Canine Renal Failure. In: BREITSCHWERDT, E. B. Nephrology and urology. New York: Churchill Livingstone, 1986. p. 151-176.

OSBORNE, C. A.; STEVENS, J.B.; LULICH, J.P. A clinician's analysis of urinalysis p.136205. In: OSBORNE, C. A.; FINCO, D.R. (ed.) Canine and Feline Nephrology and Urology. 2th. Philadelphia: Willimas \& Willkins, 1995.

ORTEGA, T.M.; et al. Systemic arterial blood pressure and urine protein/cratinine ratio in dogs with hyperadrenocorticism. J. Am. Vet. Med. Assoc. n.15, p.1724-1729, 1996.

POLZIN, D.J.; OSBORNE, C.A. Pathophysiology of renal failure and uremia p.119-127 In: OSBORNE, C. A; FINCO, D.R. (ed.) Canine and Feline Nephrology and urology. 2 th. Philadelphia: William \& Wilkins, 1995.

POLZIN, D.J.; OSBORNE, C.A.; BARTGES, J.W. Chronic renal failure p.1634-1662. In: ETTINGER, S. J.; FELMAN, E. C (ed.) Textbook of veterinary internal medicine. 5 th. Philadelphia: W. B. Saunders, 2000. v.2. 
POLZIN, D.J.; OSBORNE, C.A.; ROSS S. Chronic renal failure p.1756-1785 In: ETTINGER S.J.; FELDMAN E.C. (ed.) Textbook of veterinary internal medicine. 6th. Philadelphia: W. B. Saunders, 2005.v.2.

REGO, A.B.A.S. Microalbuminúria em cães com insuficiência renal crônica: relação com pressão sangüínea sistêmica. 2006, 97f. Dissertação (Mestrado em medicina veterinária), Faculdade de Medicina Veterinária e Zootecnia, Universidade de São Paulo.

RIGOIR, S. An update on uremic toxins. Kidney Int. n.52:S2-S4,1997.

RODRIGUEZ, F.F.; TESOURO, D.M.; RODRIGUEZ, S.M. Concentrations of 2,3diphosphoglycerate (2,3-DPG) in canine blood (healthy dogs, dogs with cardiopulmonary insufficiency and dogs with renal insufficiency). Zentralbl veterinarmed b, n.41, p. 9-16, 1994.

ROSS, L. Hypertension and chronic renal failure. Sem. Vet. Med. Surg. n.7, p.221-226, 1992.

SCHIFFRIN, E.L.; LIPMAN, M.L.; MANN, J.F.E. Chronic Kidney Disease. Circ. Res. n.116, p.85-97, 2007.

SCHLAICH, M.P.; et al. Sympathetic activation in chronic renal failure. J. Am. Soc. Nephrol. n.20, p.933-999, 2009.

SCOTT, A.N.D. Oxidative stress and chronic kidney disease. J. Vet. Clin. North Small Anim. Pract. 38:157-166. 2008.

SENIOR, D. F. Doenças do sistema urinário, In: DUNN, J. K. Tratado de medicina de pequenos animais. São Paulo: Rocca, 2001. p. 914-622.

SENIOR, D. F. Management of chronic renal failure in the dog. The compendium colletion. Veterinary Learning System, Treaton, NJ. 1994.

SHIMIZU, M.H.M. A N-acetilcisteína atenua a progressão da doença renal crônica. 2005, 105f.. Tese (Doutorado em medicina), Faculdade de Medicina Ribeirão Preto, Universidade de São Paulo.

SHAUL, G.; MASSARY, S.; SMORGORZEWSKI, M. Dysfunction of polymorphonuclear leukocytes in uremia: role of parathyroid hormone. Kidney International, New York, v. 59, S-195-196, 2001.

STEPIEN, R. L. Hypertension in cats and dogs. In: ANNUAL WALTHAN DIETS, SYMPOSION, 26. Small Animal Cardiology 2002. Ohio, USA.Proceedings... Disponível em:

http://www.vin.com/proceedings/Proceedings.plx?CID=WALTHAMOSU2002\&PID=2989 . Acesso em: 27 set. 2009.

SILVA, S.R.R. Pressão arterial e sua relação com a homeostase de sódio em cães com insuficiência renal crônica. 2002, 37f. Dissertação (Mestrado em medicina veterinaria). Faculdade de Ciências Agrárias e Veterinárias, Universidade Estadual Paulista, Jaboticabal. 
STILES, J.; POLAIN, D.J.; BISTNER, S.I. The prevalence of retinopathy in cats with systemic hypertension and chronic renal failure or hyperthyroidism. J. Am. Anim. Hosp. Assoc. n.30, p.64-572, 1994.

STRUBLE, A.L.; FELDMAN, E.C.,; NELSON, R.W.; KASS, P.H. Systemic hypertension and proteinúria in dogs with diabetes mellitus. J. Am. Vet. Med. Assoc. n.213, p.822-825, 1998.

SUTTON, R.A.L.; DIRKS, J.H. 1996. Disturbances of calcium and magnesium metabolism p.1038-1085. In: BRENNER, B. M.; RECTOR, F.C. The Kidney. 5th. Philadelphia: W. B. Saunders, 1996.

TILLEY, L. Diagnosing and treating hypertension Proceedings... CVC. 2008. Disponível em: < http://veterinarycalendar.dvm360.com/avhc/Medicine/Diagnosing-and-treatinghypertension-Proceedings/ArticleStandard/Article/detail/588617 >. Acesso em:10 set. 2009. 2

TOTO, R.D.; et al. Strict blood pressure control and progression of renal disease in hypertensive nephroesclerosis. Kidney Int. n.48, p.851-589, 1995.

VANHOLDER, R.; SMET, R. Pathophysiologic effect of uremic retention solutes. J. Am. Soc. Neprhol. n.10, p.1815-1823, 1999.

VANHOLDER, R.; LAECKE, S.V. What is new in uremic toxicity? Pediatr. Nephrol. n.23, p.1211-1221, 2008.

WATSON, A.D.J.; CHURCH, D.B. Postprandial changes in plasma urea and creatine concentrations in dogs. Am. J. Vet. Res. n.2, p.1876-80, 1981.

WEHNER, A., HARTMANN, K.; HIRSCHBUGER, J. Associations between proteinuria, systemic hypertension and glomerular filtration rate in dogs with renal and non-renal diseases. Vet. Rec. n.162, p.223-224, 2008.

WHITE, V.; FASS, G.; BONE, J. M. Renal pathology and proteinúria determine progression in untreated mild/moderate chronic renal failure. Q. J. Med. n.67, p.343-354, 1988.

$\mathrm{XU}$, J.; et al. Renalase is a novel, soluble monoamine oxidase that regulates cardiac function and blood pressure. J. Clin. Invest. n.115, p.1275-1280, 2005.

ZATZ, R. Insuficiência renal crônica p.649-659. In: ZATZ, R. (ed.) Fisiopatologia renal. São Paulo: Atheneu, 2000. 
